\title{
Antioxidant Activity of Aqueous Extracts of Different Caffeine Products
}

\author{
Abd El-Moneim M.R. AFIFY, Emad A. SHALABY, Hossam S. EL-BELTAGI* \\ Cairo University, Faculty of Agriculture, Department of Biochemistry, P. Box 12613, Gamma \\ st, Giza, Cairo, Egypt; lbltg@yahoo.com ( ${ }^{*}$ corresponding author)
}

\begin{abstract}
The antioxidant activity of water extracts (cold and hot) of six caffeine products were carried out. The extracts were screened for total polyphenol contents and antioxidant activity using DPPH, ABTS methods and reducing power method at 50 and $100 \mu \mathrm{g} / \mathrm{ml}$ after 15 min and 30 min using DPPH, ABTS BHA and Caffeine as standard compounds. The results indicated that, the hot water extracts for different caffeine products showed higher antioxidant activity than those of cold extracts and this activity was time and concentration dependent. In addition, the activity was higher against ABTS radical more than DPPH and reducing power methods. Also, there is a positive correlation between the antioxidant and reducing compounds presented in water extracts of different caffeine products. The results of HPLC showed that fresh tea leaves are rich in flavanol monomers known as catechins. The most abundant catechin derivatives in green tea are EGC, EGCG and GC. On the other hand EGCG and GC are major catechin derivative in different caffeine product except El-Fakher tea and Cacao. Generally, these beverages had high antioxidant capacities and total phenolic contents, and could be important dietary sources of antioxidant phenolic for prevention of diseases caused by oxidative stress.
\end{abstract}

Keywords: caffeine product, antioxidant activity, phenolic contents

Abbreviations: DPPH: 2, 2 diphenyl-1-picrylhydrazyl; ABTS: 2,2'- azino-bis (ethylbenzthiazoline-6-sulfonic acid); BHA: butylated hydroxyl anisole

\section{Introduction}

Tea is derived from terminal three leaves of shoots of tea plant Camellia sinensis (L.) O. Kuntze (syn. Thea sinensis L.) family Theaceae. It is the most popular non-alcoholic beverage in the world (Longo et al., 2008). Recent experimental studies have recognized that tea exhibits a significant health protecting activity due to its high polyphenol content (Manzocco et al., 1998). Tea polyphenols are the most significant group of tea components and have a wide range of pharmaceutical properties including antioxidative, anticarcinogenic and antiarteriosclerotic (Atoui et al., 2005; Dufresne and Farnworth, 2001). A number of dissimilar chemical reactions initiated by an enzyme, polyphenol oxidase during fermentation, are of practical value in commercial manufacture of black tea. The primary polyphenols are oxidized during the fermentation process and are transformed to compounds with tanning properties. The oxidized polyphenols in black tea are responsible for briskness, strength, color, taste and pungency of the black tea infusion. These polyphenols remain intact in green tea as steaming of leaves following plucking in green tea manufacture inactivates the enzyme polyphenol oxidase. The natural polyphenols in green tea include (-)-epigallocatechin-3- gallate (EGCG), (-)-epigallocatechin (EGC), (-)-epicatechin-3- gallate (ECG), and epicatechin (EC). The highest concentration is of EGCG followed by EGC, ECG and EC in decreasing order (Bradfield et al., 1948; Nakabayashi, 1991). The pharmacological importance of these catechins decreases in the order of EGCG, EGC, ECG and EC. Other minor catechins, (+)-gallocatechin (GC), (-)-gallocatechin gallate (GCG), (-)-catechin gallate (CG) and (+)-catechin (C) are also present in tea (Yamamoto et al., 1997). The green tea contains 30 to $42 \%$ polyphenols on the dry weight basis and a cup of green tea contains about 300 to $400 \mathrm{mg}$ of polyphenols (Balentine et al., 1997). In fact, evidence obtained from archeological investigation has found that tea has been consumed by humans for over 500,000 years (McKenna et al., 2000). Tea is particularly rich in polyphenols, including catechins, theaflavins and thearubigins, which are thought to contribute to the health benefits of tea. Tea polyphenols act as antioxidants in vitro by scavenging reactive oxygen and nitrogen species and chelating redox-active transition metal ions. It is well known that free radical induced oxidative stress is an important factor in the etiology of many pathological processes. Much attention has been focused on the antioxidants in food that may have beneficial physiological effects. Polyphenols constitute an important source of dietary antioxidants, being distributed widely in fruits, vegetables, cereals and beverages including red wine, tea, coffee and cocoa (Richelle et al., 2000). Roasting markedly affects the composition of the coffee polyphenols through the Maillard reaction and confers to coffee its pleasant taste and aroma (Richelle et al., 2000). In addition, carbohydrate caramelization and pyrolysis of organic compounds occur (Belitz and Grosch, 1999). However, although natural antioxidants are lost during heating, 
118

the overall antioxidant properties of coffee brews can be maintained or enhanced by the formation of new antioxidants such as the Maillard reaction products (Nicoli et al., 1997a). Tea is found in many different varieties however, the most commonly consumed are black, green and oolong tea. The differences between them are related to the way that the leaves are processed during manufacture. Green tea is unfermented, with the leaves being heated or steamed soon after being picked to prevent the fermentation that takes place with black tea (Segal, 1996). Black tea is simply fermented green tea which is prepared through a method of rolling that releases juices and enzymes from the leaves which begins the fermentation process. Oolong tea is partially fermented green tea, providing a mid-point between green and black tea (Segal, 1996).

Green tea is rich in catechins which are a class of polyphenols with a flavonoid structure (McKenna et al., 2000). Much of the attributed therapeutic benefits of green tea are due to the presence of four major catechins - epicatechin (EC), epigallocatechin (EGC), epicatechin gallate (ECG) and epigallocatechin gallate (EGCG). It is the phenolic structure of the catechins that contribute to their potent antioxidant activity because they are able to bind to metal ions and prevent their participation in peroxidase reactions (Abdel-Rahim and El-Beltagi, 2010; Afify and Shalaby, 2009; Afify et al., 2011; Cooper et al., 2005; Shallan et al., 2010a, 2010b). In addition, they act as free radical scavengers, regenerate $\alpha$-tocopherol and terminate lipid peroxidation chain reactions (Abdel-Rahim and ElBeltagi, 2011; El-Beltagi and Mohamed, 2010; El-Beltagi et al., 2011; Mohamed et al., 2010; Stewart et al., 2005). Green tea solids are comprised of approximately 30\% $42 \%$ catechins with a typical cup of green tea containing 10-30 mg EGCG (McKenna et al., 2000).

The aim of the current study was to investigate the relationship between antioxidant capacity (Using three different mechanisms) and total phenolic content, reducing compounds and catechin derivative of aqueous extracts of different caffeine products.

\section{Materials and methods}

Chemical reagents

All chemicals and reagents were of analytical grade and obtained from either Sigma-Aldrich or Merck Chemical Co. (Darmstadt, Germany).

\section{Sample collection}

Gawhara green tea, Ahmed tea, El-Arosa tea, El-Fakher tea, Abd El-Maboed Coffee and Koruna Cacao were collected from traditional market, Giza, Egypt.

\section{Preparation of extract}

A known weight of the dried and grinded samples (Caffeine products) was extracted three successive times with hot water $\left(100^{\circ} \mathrm{C}\right)$ and cold water $\left(4^{\circ} \mathrm{C}\right)$ in dark place (Flask covered with aluminum foil) at room temperature $\left(25^{\circ} \mathrm{C}\right)$. The collected extracts were filtered using filter paper (Whatman number 102, $18 \mathrm{~cm}$ ), Filtrate was evaporated to remove the water solvents using rotary evaporator, and the obtained residues (crude extracts) were kept in refrigerator at $\left(4^{\circ} \mathrm{C}\right)$ until use (Rossenthaler, 1930).

\section{Determination of total phenolic content}

Phenolic compounds were determined based on a method described by Singleton et al. (1999). Briefly, a known weight was extracted with distilled water. $1 \mathrm{ml}$ of distilled water extract was mixed with $1 \mathrm{ml}$ of Folin Ciocalteu reagent. After $3 \mathrm{~min}, 1 \mathrm{ml}$ of saturated sodium carbonate solution (20\%) was added to the mixture and adjusted to $10 \mathrm{ml}$ with distilled $\mathrm{H}_{2} \mathrm{O}$. The reaction mixture was kept in the dark for $1 \mathrm{~h}$ with intermittent shaking. The absorbance was measured at $725 \mathrm{~nm}$ using a spectrophotometer (Jenway, UV/Visible 1613). Phenolic contents were calculated on the basis of the standard curve for Gallic acid as stander.

\section{Determination of total reducing compounds}

Total reducing compounds were determine by titration of tea extracts using iodine as oxidizing agent and starch as indicator and expressed ascorbic acid as recorded by $\mathrm{Da}$ vies et al. (1991).

\section{Assay of antioxidant activities}

Antioxidant activity of different extracts was determined using the following methods:

\section{DPPH radical assay}

Scavenging effect of 2, 2 diphenyl-1-picrylhydrazyl (DPPH) radical was measured by the method of Chou et al. (2009). Where, $0.1 \mathrm{ml}$ of $1 \mathrm{mM}$ methanol solution of DPPH was incubated with various concentrations of dry sample crude extract ( 50 and $100 \mu \mathrm{g} / \mathrm{ml}$ ). After 30 and 60 min incubation periods at room temperature, absorbance of the resulting solution was recorded at $517 \mathrm{~nm}$. DPPH radical scavenging activity was expressed as the inhibition percentage and was calculated as (absorbance of control absorbance of sample/absorbance of control) $\times 100$. Standard butylated hydroxyl anisole (BHA) was used for comparison and the dose response curve of promising extract compared with stander compounds at different concentrations were carried out.

\section{ABTS radical cation scavenging assay}

This assay was based on the ability of different substances to scavenge 2,2'- azino-bis (ethylbenzthiazoline-6sulfonic acid (ABTS ${ }^{+}$) radical cation in comparison to a standard (BHA, at 50 and $100 \mu \mathrm{g} / \mathrm{ml}$ ). The radical cation was prepared by mixing a $7 \mathrm{mM}$ ABTS stock solution with $2.45 \mathrm{mM}$ potassium persulfate $(1 / 1, \mathrm{v} / \mathrm{v})$ and leaving the mixture for 4-16 hrs until the reaction was completed and the absorbance was stable. The ABTS ${ }^{\square+}$ solution was diluted with ethanol to an absorbance of $0.700 \pm 0.05$ at $734 \mathrm{~nm}$ for measurements. The photometric Assay was conducted 
on $0.9 \mathrm{ml}$ of ABTS ${ }^{\square+}$ solution and $0.1 \mathrm{ml}$ of tested samples (50 and $100 \mu \mathrm{g} / \mathrm{ml}$ in $\mathrm{MeOH}$ solution) and mixed for 45 $\mathrm{s}$, measurements were taken at $734 \mathrm{~nm}$ after $1 \mathrm{~min}$. The antioxidative activity of the tested samples was calculated by determined the decrease in absorbance at different concentrations by using the following equation:

\section{$\mathrm{E}=((\mathrm{Ac}-\mathrm{At}) / \mathrm{Ac}) \times 100$}

where: At and Ac are the respective absorbance of tested samples and $\mathrm{ABTS}^{\square+}(\operatorname{Re}$ et al., 1999).

\section{Reducingpower}

The reducing power was determined by the method of Chou et al. (2009). The distilled water extracts $(0.25,50$ and $100 \mu \mathrm{g} / \mathrm{ml}$ ) was mixed with $0.25 \mathrm{ml}$ of sodium phosphate buffer ( $200 \mathrm{mM}, \mathrm{pH} 6.6)$ and $0.25 \mathrm{ml}$ of $1 \%$ potassium ferricyanide. The mixture was incubated at $50^{\circ} \mathrm{C}$ for $20 \mathrm{~min}$. then $0.25 \mathrm{ml}$ of $10 \%$ trichloroacetic acid was added to the mixture to stop the reaction, the mixture was centrifuged at $3000 \mathrm{rpm}$ for $10 \mathrm{~min}$. The supernatant $(0.5$ $\mathrm{ml}$ ) was mixed with $0.4 \mathrm{ml}$ of deionized water and 0.1 $\mathrm{ml}$ of $0.1 \%$ ferric chloride solution to allow for standing for $10 \mathrm{~min}$. The absorbance was measured at $700 \mathrm{~nm}$. A higher absorbance indicated a higher reducing power, and standard BHA was used for comparison.

\section{HPLC analysis of catechin derivatives}

The analytical determinations of phenolic compounds for different caffeine products were carried out using reverse phase-high performance liquid chromatography in isocratic mode. The Waters HPLC system equipped with automated gradient controller, 510 pumps, U6K injector, 481 detector, 746 data module and Waters $\mu$-bondapak C18 column $(3.9 \times 300 \mathrm{~mm})$, was used for the analysis. Elution was carried out at ambient temperature between 24 to $28^{\circ} \mathrm{C}$ using water: methanol: acetic acid (70:30: 0.5 ) as a mobile phase at a flow rate $1.0 \mathrm{ml} / \mathrm{min}$. All extracts were prepared in triplicate and each extract was analyzed in triplicate. The UV detection was carried out at 280 $\mathrm{nm}$.

\section{Statistical analysis}

All experimental results were expressed as means \pm S.D. Analysis of variance was performed by ANOVA procedures. The results with $\mathrm{P}<0.05$ were regarded to be statistically significant. Data were statistically analyzed using Co state Statistical Package (Anonymous, 1989).

\section{Results and discussion}

\section{Total phenolic content}

Six kinds of commercial caffeine products (El-Gawhara green tea, Ahmed tea, El-Arosa tea, El-Fakher tea, Abd ElMaboed Coffee and Koruna Cacao) infusions were obtained from traditional markets in Giza-Cairo, which represent main categories of the infusions made in Egypt. The total phenolic contents of 6 infusions were estimated using the Folin-Ciocalteu method, which relies on the trans- fer of electrons from phenolic compounds to the FolinCiocalteu reagent in alkaline medium, and it is a simple and rapid method (Singleton and Rossi, 1965). As shown in Tab. 1, the total phenolic contents varied from $1.68 \pm$ 0.06 in El-Fakher tea to $2.28 \pm 0.06$ in El-Gawhara green tea, gallic acid equivalent (g GAE)/100g. El-Gawhara green tea and Abd El-Maboed Coffee had the highest total phenolic content $(2.28 \pm 0.06$ and $2.28 \pm 0.07 \mathrm{~g} \mathrm{GAE} /$ $100 \mathrm{~g}$ respectively), El-Fakher tea showed the lowest total phenolic content $(1.68 \pm 0.06 \mathrm{~g} \mathrm{GAE} / 100 \mathrm{~g})$ in cold water tested samples. While in the hot water tested samples, the highest total phenolic content was the green tea and Ahmed tea (2.44 \pm 0.03 and $2.38 \pm 0.05 \mathrm{~g} \mathrm{GAE} / 100 \mathrm{~g})$, El-Arosa tea recorded the lowest total phenolic content $(1.39 \pm 0.04 \mathrm{~g} \mathrm{GAE} / 100 \mathrm{~g})$.

Reducing compounds (including all water soluble reducing compounds) percentage in cold water extracts recorded the highest values in Koruna Cacao $(28.3 \% \pm 0.22)$ and El-Gawhara green tea $(25.8 \% \pm 0.22)$, while Ahmed tea showed the lowest value $(5.28 \% \pm 0.07)$. Therefore, the reducing compound percentage in hot water extracts showed the highest values in El-Fakher tea $(34.3 \pm 0.51)$ and Koruna cacao $(26.4 \pm 0.25)$, while Ahmed tea also showed the lowest value $(6.6 \pm 0.12)$.

\section{Antioxidant activities}

The antioxidant activity of caffeine products for cold and hot water extracts were measured using in vitro assays including the reducing power assay and the assay evaluating the free radical scavenging capacity such as the DPPH and ABTS methods with two concentrations 50 and $100(\mu \mathrm{g} / \mathrm{ml})($ Tab. $2,3,4)$. The results revealed that the antioxidant activity of water extracts were time and concentration dependent. In addition to, the antioxidant

Tab. 1. Total phenolic contents and Percentage of reducing compounds of caffeine products

\begin{tabular}{|c|c|c|c|}
\hline Solvent & Samples & $\begin{array}{l}\text { Total Phenolic } \\
\text { contents (g } \\
\text { GAE/100g d.w.) }\end{array}$ & $\begin{array}{c}\text { Reducing } \\
\text { compounds } \\
\%\end{array}$ \\
\hline \multirow{6}{*}{$\begin{array}{l}\text { Cold } \\
\text { water }\end{array}$} & El-Gawhara green tea & $2.28 \pm 0.06$ & $25.8 \pm 0.22$ \\
\hline & Ahmed tea* & $1.75 \pm 0.03$ & $5.28 \pm 0.07$ \\
\hline & El-Arosa tea* & $2.14 \pm 0.05$ & $19.8 \pm 0.15$ \\
\hline & El-Fakher tea* & $1.68 \pm 0.06$ & $23.76 \pm 0.14$ \\
\hline & Abd El-Maboed coffee & $2.28 \pm 0.07$ & $16.3 \pm 0.12$ \\
\hline & Koruna cacao & $1.76 \pm 0.04$ & $28.3 \pm 0.22$ \\
\hline \multirow{6}{*}{$\begin{array}{c}\text { Hot } \\
\text { water }\end{array}$} & El-Gawhara green tea & $2.44 \pm 0.03$ & $11.88 \pm 0.17$ \\
\hline & Ahmed tea* & $2.38 \pm 0.05$ & $6.6 \pm 0.12$ \\
\hline & El-Arosa tea* & $1.39 \pm 0.04$ & $14.52 \pm 0.11$ \\
\hline & El-Fakher tea* & $1.87 \pm 0.05$ & $34.3 \pm 0.51$ \\
\hline & Abd El-Maboed coffee & $1.87 \pm 0.07$ & $15.28 \pm 0.17$ \\
\hline & Koruna cacao & $2.12 \pm 0.04$ & $26.4 \pm 0.25$ \\
\hline \multicolumn{2}{|r|}{ Standard (BHA) } & $2.28 \pm 0.07$ & $25.8 \pm 0.16$ \\
\hline \multicolumn{2}{|c|}{ Standard (Caffeine) } & $1.75 \pm 0.03$ & $5.28 \pm 0.09$ \\
\hline \multicolumn{2}{|c|}{ LSD $5 \%$} & 0.086 & 0.40 \\
\hline
\end{tabular}

* Black tea; Ahmed tea (import tea from England), El-Arosa tea (export tea), El-fakher tea (popular tea) 
120

activities determined by the three methods proved that hot extracts showed high antioxidant activities than cold extracts with different samples (green tea, Ahmed tea ElArosa tea, El-Fakher tea, Coffee, Cacao) compared with BHA and Caffeine as standard. The antioxidant activities of green tea cold water measured by the two radical scavenging methods (DPPH and ABTS) are much closed to each other $(71.2 \% \pm 0.38,74.5 \% \pm 0.48$, at $50(\mu \mathrm{g} / \mathrm{ml})$ after $15 \mathrm{~min}$ ) (Tab. 1, 2, 3). On the same time as a general trend hot extracts showed more antioxidant activities than cold extracts measured at concentration of $50(\mu \mathrm{g} /$ $\mathrm{ml})$ such as cold green tea $(71.2 \pm 0.38)$ against hot green tea $(81.3 \pm 0.39)$, cold Ahmed tea $(70.5 \pm 0.32)$ against hot
Ahmed tea (88.2 \pm 0.42$)$. This high level of antioxidant activities in tea is consistent with several other reports of hot water extract of black and green tea (Atoui et al., 2005; Dreosti, 1996).

Ahmed tea and Coffee showed the highest antioxidant activities at $100 \mu \mathrm{g} / \mathrm{ml}(81.9 \% \pm 0.58,81.8 \% \pm 0.66)$ after $30 \mathrm{~min}$ in DPPH method with cold water extracts. While with hot extracts; Ahmed tea and Coffee showed the highest antioxidant activates at $(100 \mu \mathrm{g} / \mathrm{ml})$ concentration, $(89.7 \pm 0.32,90.5 \pm 0.24)$ after 30 min respectively. The study reveals that the consumption of these spices would exert several beneficial effects by virtue of their antioxidant activity (Nicoli et al., 1997a; b).

Tab. 2. Antioxidant activity (\%) of cold and hot extracts of caffeine sources against DPPH method

\begin{tabular}{|c|c|c|c|c|c|}
\hline \multirow[t]{2}{*}{ Solvent } & \multirow[t]{2}{*}{ Samples } & \multicolumn{2}{|c|}{$\begin{array}{c}\text { Antioxidant activity (\%) } \\
\text { At } 50 \mu \mathrm{g} / \mathrm{ml}\end{array}$} & \multicolumn{2}{|c|}{$\begin{array}{c}\text { Antioxidant activity (\%) } \\
\text { At } 100 \mu \mathrm{g} / \mathrm{ml}\end{array}$} \\
\hline & & $15 \mathrm{~min}$ & $30 \mathrm{~min}$ & $15 \mathrm{~min}$ & $30 \mathrm{~min}$ \\
\hline \multirow{6}{*}{ Cold water } & El-Gawhara green tea & $71.2 \pm 0.38$ & $72.9 \pm 0.41$ & $76.1 \pm 0.48$ & $79.3 \pm 0.42$ \\
\hline & Ahmed tea* & $70.5 \pm 0.32$ & $74.6 \pm 0.45$ & $70.6 \pm 0.47$ & $81.9 \pm 0.58$ \\
\hline & El-Arosa tea* & $45.1 \pm 0.28$ & $53.7 \pm 0.37$ & $51.7 \pm 0.49$ & $73.2 \pm 0.41$ \\
\hline & El-Fakher tea* & $61 \pm 0.23$ & $61.9 \pm 0.33$ & $61.9 \pm 0.39$ & $75.6 \pm 0.39$ \\
\hline & Abd El-Maboed coffee & $69 \pm 0.45$ & $74.5 \pm 0.38$ & $68.9 \pm 0.34$ & $81.8 \pm 0.66$ \\
\hline & Koruna cacao & $33.9 \pm 0.31$ & $45.1 \pm 0.50$ & $39.4 \pm 0.45$ & $66.6 \pm 0.52$ \\
\hline \multirow{6}{*}{ Hot water } & El-Gawhara green tea & $81.3 \pm 0.39$ & $87.3 \pm 0.62$ & $79.5 \pm 0.15$ & $87.3 \pm 0.42$ \\
\hline & Ahmed tea* & $88.2 \pm 0.42$ & $88.6 \pm 0.58$ & $88.3 \pm 0.20$ & $89.7 \pm 0.32$ \\
\hline & El-Arosa tea* ${ }^{*}$ & $75.5 \pm 0.37$ & $77 \pm 0.56$ & $75.8 \pm 0.22$ & $84.6 \pm 0.29$ \\
\hline & El-Fakher tea* & $88.3 \pm 0.36$ & $89.7 \pm 0.64$ & $88.6 \pm 0.17$ & $89.5 \pm 0.18$ \\
\hline & Abd El-Maboed coffee & $88.6 \pm 0.21$ & $88.6 \pm 0.51$ & $88.8 \pm 0.26$ & $90.5 \pm 0.24$ \\
\hline & Koruna cacao & $78 \pm 0.20$ & $79.16 \pm 0.43$ & $77.1 \pm 0.22$ & $88.3 \pm 0.21$ \\
\hline \multicolumn{2}{|r|}{ Standard (BHA) } & $77.4 \pm 0.20$ & $80.5 \pm 0.58$ & $80.4 \pm 0.24$ & $86.9 \pm 0.35$ \\
\hline \multicolumn{2}{|r|}{ Standard (Caffeine) } & $33.2 \pm 0.12$ & $40.7 \pm 0.36$ & $36.3 \pm 0.15$ & $47.7 \pm 0.17$ \\
\hline \multicolumn{2}{|r|}{ LSD $5 \%$} & 0.496 & 0.94 & 0.35 & 0.49 \\
\hline
\end{tabular}

${ }^{*}$ Black tea; Ahmed tea (Imported tea from England), El-Arosa tea (exported tea), El-fakher tea (popular tea)

Tab. 3. Antioxidant activity (\%) of cold and hot extracts of caffeine sources against ABTS method

\begin{tabular}{|c|c|c|c|c|c|}
\hline \multirow[t]{2}{*}{ Solvent } & \multirow[t]{2}{*}{ Samples } & \multicolumn{2}{|c|}{$\begin{array}{c}\text { Antioxidant activity (\%) } \\
\text { At } 50 \mu \mathrm{g} / \mathrm{ml}\end{array}$} & \multicolumn{2}{|c|}{$\begin{array}{c}\text { Antioxidant activity (\%) } \\
\text { At } 100 \mu \mathrm{g} / \mathrm{ml}\end{array}$} \\
\hline & & $15 \mathrm{~min}$ & $30 \mathrm{~min}$ & $15 \mathrm{~min}$ & $30 \mathrm{~min}$ \\
\hline \multirow{6}{*}{ Cold water } & El-Gawhara green tea & $74.5 \pm 0.48$ & $76.5 \pm 0.31$ & $80.8 \pm 0.41$ & $84.2 \pm 0.45$ \\
\hline & Ahmed tea* & $65.3 \pm 0.46$ & $65.6 \pm 0.41$ & $77.4 \pm 0.34$ & $78.5 \pm 0.38$ \\
\hline & El-Arosa tea* & $50.3 \pm 0.31$ & $52.4 \pm 0.32$ & $55.0 \pm 0.20$ & $72.2 \pm 0.39$ \\
\hline & El-Fakher tea* & $60.5 \pm 0.39$ & $59.3 \pm 0.32$ & $68.9 \pm 0.28$ & $67.8 \pm 0.35$ \\
\hline & Abd El-Maboed coffee & $68.1 \pm 0.42$ & $68.0 \pm 0.36$ & $78.6 \pm 0.38$ & $82.5 \pm 0.39$ \\
\hline & Koruna cacao & $42.1 \pm 0.35$ & $45.1 \pm 0.48$ & $50.6 \pm 0.39$ & $67.8 \pm 0.30$ \\
\hline \multirow{6}{*}{ Hot water } & El-Gawhara green tea & $82.5 \pm 0.32$ & $83.6 \pm 0.34$ & $88.3 \pm 0.34$ & $89.6 \pm 0.29$ \\
\hline & Ahmed tea* & $86.5 \pm 0.42$ & $87.5 \pm 0.21$ & $85.9 \pm 0.40$ & $89.1 \pm 0.28$ \\
\hline & El-Arosa tea* & $80.0 \pm 0.49$ & $82.5 \pm 0.31$ & $85.6 \pm 0.37$ & $84.8 \pm 0.38$ \\
\hline & El-Fakher tea* & $85.3 \pm 0.29$ & $91.8 \pm 0.53$ & $88.3 \pm 0.32$ & $91.3 \pm 0.40$ \\
\hline & Abd El-Maboed coffee & $84.7 \pm 0.30$ & $85.6 \pm 0.32$ & $87.3 \pm 0.35$ & $88.5 \pm 0.37$ \\
\hline & Koruna cacao & $80.2 \pm 0.38$ & $82.4 \pm 0.30$ & $85.6 \pm 0.25$ & $88.9 \pm 0.23$ \\
\hline \multicolumn{2}{|r|}{ Standard (BHA) } & $80.2 \pm 0.39$ & $81.6 \pm 0.51$ & $85.9 \pm 0.23$ & $88.7 \pm 0.19$ \\
\hline \multicolumn{2}{|r|}{ Standard (Caffeine) } & $50.1 \pm 0.16$ & $50.9 \pm 0.21$ & $54.3 \pm 0.18$ & $58.6 \pm 0.14$ \\
\hline \multicolumn{2}{|r|}{ LSD $5 \%$} & 0.59 & 0.62 & 0.54 & 0.52 \\
\hline
\end{tabular}

* Black tea; Ahmed tea (imported tea from England), El-Arosa tea (exported tea), El-fakher tea (popular tea) 
The highest antioxidant activities of tea product due to the high content of total phenolic compounds as well as the reducing compounds such as cold green tea, $(2.28 \pm 0.06$; $25.8 \pm 0.22)$; and cold coffee $(2.28 \pm 0.07,16.3 \pm 0.12)$.

Reducing power of a compound served as a significant indicator of its potential antioxidant activity. In concentration 50 and $100(\mu \mathrm{g} / \mathrm{ml})$, the antioxidant activity of reducing powers of Abd El-Maboed coffee and El-Fakher tea in cold water extract showed the maximum values $(62.10 \pm 0.19)$ and $(55.80 \pm 0.09)$, while in hot water extracts El-Gawhara green tea and Koruna cacao were the higher values $(70.65 \pm 0.15)$ and $(62.38 \pm 0.15)$ in the concentration $50(\mu \mathrm{g} / \mathrm{ml})$ (Tab. 4). Also in concentration 100 $(\mu \mathrm{g} / \mathrm{ml})$, the antioxidant activity of reducing powers of ElGawhara green tea and El-Fakher tea recorded the higher antioxidant activities $(91.64 \pm 0.15)$ and $(90.84 \pm 0.14)$. Specifically, reducing powers of hot water extracts showed good antioxidant activities than those of cold water extracts and contained a lot of phenolic compounds. Hence, it is supposed that those antioxidant activities may be due to high level of total phenolic compounds (Hwang et al., 2010).

Tab. 4. Relative percentage of antioxidant activity of cold and hot water extracts determined by reducing power

\begin{tabular}{|c|c|c|c|}
\hline \multirow{2}{*}{ Solvent } & \multirow{2}{*}{ Samples } & \multicolumn{2}{|c|}{ Antioxidant activity (\%) } \\
\hline & & $50(\mu \mathrm{g} / \mathrm{ml})$ & $100(\mu \mathrm{g} / \mathrm{ml})$ \\
\hline \multirow{6}{*}{$\begin{array}{l}\text { Cold } \\
\text { water }\end{array}$} & El-Gawhara green tea & $42.6 \pm 0.11$ & $70.0 \pm 0.13$ \\
\hline & Ahmed tea* & $50.89 \pm 0.12$ & $72.51 \pm 0.17$ \\
\hline & El-Arosa tea* ${ }^{*}$ & $41.2 \pm 0.10$ & $71.65 \pm 0.16$ \\
\hline & El-Fakher tea* & $55.80 \pm 0.09$ & $82.30 \pm 0.37$ \\
\hline & Abd El-Maboed coffee & $62.10 \pm 0.19$ & $88.40 \pm 0.34$ \\
\hline & Koruna cacao & $42.70 \pm 0.02$ & $74.90 \pm 0.16$ \\
\hline \multirow{6}{*}{$\begin{array}{c}\text { Hot } \\
\text { water }\end{array}$} & El-Gawhara green tea & $70.65 \pm 0.15$ & $91.64 \pm 0.15$ \\
\hline & Ahmed tea* & $61.45 \pm 0.21$ & $89.61 \pm 0.11$ \\
\hline & El-Arosa tea* & $40.0 \pm 0.12$ & $70.62 \pm 0.09$ \\
\hline & El-Fakher tea* & $58.6 \pm 0.20$ & $90.84 \pm 0.14$ \\
\hline & Abd El-Maboed coffee & $60.84 \pm 0.16$ & $89.67 \pm 0.10$ \\
\hline & Koruna cacao & $62.38 \pm 0.15$ & $88.54 \pm 0.12$ \\
\hline \multicolumn{2}{|r|}{ Standard (BHA) } & $40.78 \pm 0.09$ & $87.94 \pm 0.13$ \\
\hline \multicolumn{2}{|r|}{ Standard (Caffeine) } & $30.87 \pm 0.08$ & $40.62 \pm 0.07$ \\
\hline \multicolumn{2}{|r|}{ LSD $5 \%$} & 0.26 & 0.20 \\
\hline
\end{tabular}

${ }^{*}$ Brown tea; Ahmed tea (imported tea from England), El-Arosa tea (exported tea), El-fakher tea (popular tea)

Tab. 5. Correlation coefficient between different antioxidant methods and reducing compounds as well as phenolic compounds

\begin{tabular}{|c|c|c|c|c|c|}
\hline & ABTS & DPPH & R. power & Phenolic & Red.com \\
\hline ABTS & & 0.887857 & 0.662047 & 0.79073 & 0.307982 \\
\hline DPPH & & & 0.86345 & 0.543765 & 0.371244 \\
\hline R. power & & & & 0.386846 & 0.499476 \\
\hline Phenolic & & & & & 0.351879 \\
\hline Red. com & & & & & \\
\hline
\end{tabular}

These results proved by studying correlation coefficient between antioxidants methods DPPH, ABTS and reducing power method, phenolic compound and reducing compounds as shown in Tab. 5. The results in Tab. 5 showed that, there are positive correlations between different antioxidant methods and reducing compounds in caffeine extracts. The correlation coefficients among different antioxidant methods and phenolic and reducing compounds are between 0.30 and 0.88 . There are good correlation $(r=$ more than 0.5) achieved between ABTS and DPPH methods $(\mathrm{r}=0.88)$; ABTS and phenolic compounds $(\mathrm{r}=0.79)$; DPPH, ABTS and reducing power methods $(\mathrm{r}=0.66$ and 0.86 respectively) but another trend (weak correlations; $\mathrm{r}=$ less than 0.5 ) were observed in other relations; between ABTS and Reducing compounds $(r=0.30)$; DPPH and reducing compounds $(\mathrm{r}=0.37)$; Reducing power method and reducing compounds $(\mathrm{r}=0.49)$ and Phenolic compounds and reducing compounds $(\mathrm{r}=0.35)$.

The antioxidant properties of green coffee, which are mainly due to the polyphenols, such as chlorogenic acid or caffeic acid available to act as an antioxidant can be increased (light and medium coffees) or maintained (dark coffee) by formation of new antioxidants, i.e. Millard reaction products during the roasting process. Melanoidins are brown polymers formed by the Maillard reaction during the roasting of coffee beans and account for up to $25 \%$ of the dry matter. It has recently been shown by the ABTS method that coffee melanoidins have significant antioxidant activity in vitro (Borrelli et al., 2002; Brudzynski and Miotto, 2011). Polyphenols in green tea as well as in different caffeine product possess much more potent antioxidant activity than well-known antioxidants such as vitamin $C$ and vitamin $E$. The main antioxidant found in green tea called epigallocatechin gallate, or EGCG is at least 100 times more effective than vitamin $C$ and 5 times better than vitamin $\mathrm{E}$ at protecting cells (Ahmed et al., 2004) and proposed as a cancer chemopreventative (Saffari and Sadrzadeh, 2004). Because of their high antioxidant activities, it could be speculated that these extracts will be beneficial for the diseases caused by oxidative stress. Although, EGCG has been shown to inhibit tumor growth/invasion by inhibiting the gelatinase activity (Cheng et al., 2003; Garbisa et al., 2001). There are a number of studies documenting the beneficial health effects of green tea consumption. Most of these studies place emphasis on the anti-cancer properties of green tea, which have now been attributed, at least in part, to the ability of green tea polyphenols to inhibit the gelatinases (Cheng $e t$ al., 2003; Garbisa et al., 2001). Therefore, it is tempting to suggest that green tea polyphenol EGCG or compounds derived from it may serve as lead agents in the design of more potent and effective inhibitors of collagenases for use therapeutically to block the pathogenesis of arthritis (Ahmed et al., 2004).

The dose response curves of promising sample (Green tea) compared with stander compounds were analyzed 
122

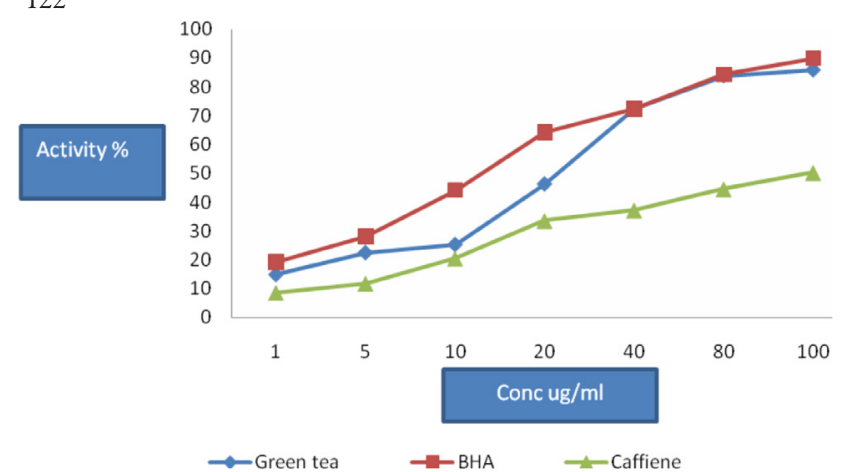

Fig. 1. The dose response curve of promising sample (Green tea) compared with stander compounds

and the results showed in Fig. 1. Revealed that, there is positive correlation between the concentration of sample and antioxidant activity against DPPH radical.

\section{HPLC analysis}

HPLC analysis of catechin and catechin derivative of tea and tea product as well as coffee and cacao showed that the major components of catechin derivative are different according to the source (Tab. 6.). The major catechin derivative in green tea are (EGC, EGCG, GC) which represents $(28.11,32.60,20.42 \%)$, while in Ahmed tea, Coffee and El-Arosa tea (EGCG, GC) are represents (30.65, $40.86 \%),(38.87,30.23 \%)$ and $(23.19,55.4$, El-Fakher tea, Cacao (GC) represents $(3.8,2.8,1.8)$, respectively. The antioxidant activity of the tea and tea product related the major component of catechin derivative which differ from product to another, on the other hand antioxidant activity in coffee and cacao may be related to the addition browning reaction during processing (Friedman et al., 2005; Kang et al., 2010; Rusak et al., 2008).

Tab. 6. Relative percentage of phenolic compounds separated by HPLC

\begin{tabular}{ccccccc}
\hline Sample no. & EGC & EGCG & GC & ECG & +C & EC \\
\hline green tea $^{28.11}$ & 32.6 & 20.42 & 2.31 & 2.17 & 14.3 \\
Ahmed tea $^{*}$ & 14.0 & 30.65 & 40.86 & 3.83 & 5.1 & 5.5 \\
El-Arosa tea $^{*}$ & 11.5 & 23.19 & 55.4 & 0.25 & 2.96 & 6.60 \\
El-Fakher tea $^{*}$ & 15.3 & 0.0 & 69.8 & 1.83 & 5.69 & 7.35 \\
Coffee & 14.0 & 38.87 & 30.23 & 7.88 & 5.50 & 3.45 \\
Cacao & 4.25 & 0.0 & 95.70 & 0.0 & 0.0 & 0.0 \\
\hline
\end{tabular}

EGC: Epigallocatechine, EGCG: Epigallocatechingallate, GC: Gallocatechin, ECG: Epicatechin gallate, $+\mathrm{C}$ : Catechin, EC: Epicatechin. ${ }^{*}$ Black tea; Ahmed tea (imported tea from England), El-Arosa tea (exported tea), El-fakher tea (popular tea)

\section{Conclusions}

It can be conclude that, the water extracts of different caffeine products had high antioxidant activity especially green tea when compared with the synthetic and natural stander and this activity was time, compounds and concentration dependent.

\section{Acknowledgments}

Authors would like to thank the management of the Faculty of Agriculture, Cairo University for ongoing cooperation to support research and providing funds and facilities necessary to achieve the desired goals of research.

\section{References}

Abdel-Rahim EA, El-Beltagi HS (2010). Constituents of apple, parsley and lentil edible plants and their therapy treatments for blood picture as well as liver and kidneys functions against lipidemic disease. Electron J Environ, Agricult Food Chem 9(6):1117-1127.

Abdel-Rahim EA, El-Beltagi HS (2011). Alleviation of hyperlipidimea in hypercholesterolic rats by lentil seeds and apple as well as parsley as semi-modified diets. Adv Food Sci 33(1):1-6.

Afify AMR, Shalaby EA (2009). Antioxidant capacity of different types of caffeine products The $1^{\text {st }}$ Euro-Med conference (Plant Natural Products: From Biodiversity to Bioindustry) held at The National Research Center Cairo Egypt, $74 \mathrm{p}$.

Afify AMR, El-Beltagi HS, Fayed SA, Shalaby EA (2011). Acaricidal activity of successive extracts from Syzygium cumini L. Skeels (Pomposia) against Tetranychus urticae Koch. Asian Pacific J Tropical Biomed 1(5):359-364.

Ahmed S, Wang N, Lalonde M, Goldberg VM, Haqqi TM (2004). Green Tea Polyphenol Epigallocatechin-3-gallate (EGCG) Differentially Inhibits Interleukin-1 $\beta$-Induced Expression of Matrix Metalloproteinase-1 and -13 in Human Chondrocytes. J Pharmacol Experimen Therapeut 308(2):767-773.

Anonymous (1989). Cohort Software Corp. Costate user manual version 3.03, Barkley CA, USA.

Atoui AK, Mansouri A, Boskou G, Kefalas P (2005). Tea and herbal infusions: Their antioxidant activity and phenolic profile. Food Chem 89:27-36.

Balentine DA, Wiseman SA, Bouwens LC (1997). The chemistry of tea flavonoids. Critic Rev Food Sci Nutri 37:693-704.

Belitz HD, Grosch W (1999). Food Chemistry. Springer-Verlag, Berlin, Germany 874-883 p.

Borrelli RC, Visconti A, Mennella C (2002). Chemical characterization and antioxidant properties of coffee melanoidins. J Agricul Food Chem 50(22):6527-6533.

Bradfield AE, Penny M, Wright WB (1948). The catechins of green tea Part II. J Chem Soc 2249.

Brudzynski K, Miotto D (2011). Honey melanoidins: Analysis of the compositions of the high molecular weight melanoidins exhibiting radical-scavenging activity. Food Chem 127(3):1023-1030.

Cheng XW, Kuzuya M, Kanda S, Maeda K, Sasaki T, Wang 
QL, Tamaya-Mori N, Shibata T, Iguchi A (2003). Epigallocatechin-3-gallate binding to MMP-2 inhibits gelatinolytic activity without influencing the attachment to extracellular matrix proteins but enhances MMP-2 binding to TIMP-2. Arch Biochem Biophy 415:126-132.

Chou HJ, Kuo JT, Lin ES (2009). Comparative antioxidant properties of water extracts from different parts of beefsteak plant (Perilla frutescens). J Food Drug Analysis 17:489-496.

Cooper R, Morré DJ, Morré DM (2005). Medicinal Benefits of Green Tea: Part II. Review of Anticancer Properties. J Altern Complement Med 11(4):639-652.

Davies MB, Austin J, Partridge DA (1991). Vitamin C: Its Chemistry and Biochemistry, The Royal Soc Chem, 48 p.

Dreosti IE (1996). Bioactive ingredients: antioxidants and polyphenols in tea. Nutr Rev 54(11):S51-S58.

El-Beltagi HES, Mohamed AA (2010). Variation in fatty acid composition, glucosinolate profile and some phytochemical contents in selected oil seed rape (Brassica napus L.) cultivars. Grasas Y Aceites 61(2):143-150.

El-Beltagi HS, Mohamed AA, Mekki BB (2011). Differences in some constituents, enzymes activity and electrophoretic characterization of different rapeseed (Brassica napus L.) cultivars. Analele Universității din Oradea-Fascicula Biologie, Tom XVIII (1):39-46.

Dufresne CJ, Farnworth ER (2001). A review of latest research findings on the health promotion properties of tea. J Nutri Biochem 12:404-421.

Friedman M, Kim SY, Lee SL, Han GP, Han JS, Lee KR, Kozukue N (2005). Distribution of catechins, theaflavines, caffeine, and theobromine in 77 teas consumed in the United States. J Food Sci 70:550-559.

Garbisa S, Sartor L, Biggin S, Salvato B, Benelli R, Albini A (2001). Tumor elatinases and invasion inhibited by the green tea flavanol epigallocatechin-3- gallate. Cancer 91:822-832.

Hwang P, Wu CH, Gau SY, Chien SY, Hwang DF (2010). Antioxidant and immune-stimulating activities of hot-water extract from seaweed Sargassum hemiphyllum. J Mater Sci Technol 18(1):41-46.

Kang KW, Oh SJ, Ryu SY, Song GY, Kim BH, Kang JS, Kim SK (2010). Evaluation of the total oxy-radical scavenging capacity of catechins isolated from green tea. Food Chem 121:1089-1094

Longo G, Karan M, Sharma PD, Rakesh DD, Vyas S, Vasisht $\mathrm{K}$ (2008). Quantitative analysis of green tea polyphenols in Indian cultivars, 275-282 p. In: Jain NK, Rahman F, Baker P (Eds.). Economic crisis in tea industry. Studium Press Llc.

Manzocco L, Anese M, Nicoli MC (1998). Antioxidant properties of tea extracts as affected by processing. LWT 31:694-698.

McKenna DJ, Hughes K, Jones K (2000). Green Tea Monograph. Altern Therapies Health Med 6(3):61-84.

Mohamed AA, Khalil AA, El-Beltagi HES (2010). Antioxidant and antimicrobial properties of kaff maryam (Anastatica hierochuntica) and doum palm (Hyphaene thebaica). Grasas Y Aceites 61(1):67-75.
Nakabayashi T (1991). Chemical components in tea leaves, $20 \mathrm{p}$. In: Nakabayashi T, Ina SK (Eds.). Chemistry and Function of Green Tea, Black Tea and Oolong tea (in Japanese). Kagaku Shuppan. Kawasaki, Japan.

Nicoli MC, Anese M, Parpinel MT, Franceschi S, Lerici CR (1997a). Loss and formation of antioxidants during food processing and storage. Cancer Lett 114:71-74.

Nicoli MC, Anese M, Manzocco L, Lerici CR (1997b). Antioxidant properties of coffee brews in relation to roasting degree. Lebensm. Wiss-Technol 30:292-297.

Re R, Pellegrini N, Proteggente A, Pannala A, Yang M, RiceEvans C (1999). Antioxidant activity applying an improved ABTS radical cation decolorization assay. Free Radical Biol Med 26:1231-1237.

Richelle M, Huynh-Ba T, Mooser V, Enslen M, Offord EA (2000). Caffeinated beverages, 102-110 p. In: Parliament TH, Ho CT, Schieberle P (Eds.). Health benefits, physiological effects and chemistry. American Chemical Society, Washington DC.

Rossenthaler L (1930). The chemical investigation of plants. Translated into English by Sudhamoy Ghosh from the Third German edition. Bell and Sons. Ltd London.

Rusak G, Komes D, Likic S, Horzic D, Kovac M (2008). Phenolic content and antioxidative capacity of green and white tea extracts depending on extraction conditions and the solvent used. Food Chem 110:852-858

Saffari Y, Sadrzadeh SM (2004). Green tea metabolite EGCG protects membranes against oxidative damage in vitro. Life Sci 74(12):1513-1518.

Segal M (1996). Tea: A Story of Serendipity. Retrieved September 27, 2005 from http://www.fda.gov/fdac/ features/296_tea.html

Shallan MA, El-Beltagi HS, Mona A, Amera TM, Sohir NA (2010a). Effect of amylose content and pre-germinated brown rice on serum blood glucose and lipids in experimental animal. Austr J Appl Sci 4(2):114-121.

Shallan MA, El-Beltagi HS, Mona A, Amera TM (2010b). Chemical evaluation of pre-germinated brown rice and whole grain rice bread. Electron J Environ, Agricult Food Chem 9(3):958-971.

Singleton VL, Rossi JA (1965). Colorimetry of total phenolics with phosphomolybdic-phosphotungstic acid reagents. Am J Enology a Viticult 16:144-158.

Singleton VL, Orthofer R, Lamuela-Raventos RM (1999). Analysis of total phenols and other oxidation substrates and antioxidants by means of Folin-Ciocalteu reagent. Met Enzymol 299:152-178.

Stewart SH, Conrod PJ, Marlatt GA, Comeau MN, Thrush C, Krank M (2005). New developments in prevention and early intervention for alcohol abuse in youth. Alcoholism: Clinical and Experimental Research.

Yamamoto T, Juneja LR, Chu DC, Kim M (1997). Chemistry and Applications of Green Tea.: CRC Press, Boca Raton, New York, USA. 